\title{
A pilot observational study measuring acute sarcopenia in older colorectal surgery patients
}

\author{
Carly Welch ${ }^{1,2^{*}} \mathbb{0}$, Carolyn A. Greig ${ }^{3,4,5}$, Zaki K. Hassan-Smith ${ }^{2,6}$, Thomas D. Pinkney ${ }^{7}$, Janet M. Lord ${ }^{1,4,5}$ \\ and Thomas A. Jackson ${ }^{1,2}$
}

\begin{abstract}
Objective: To explore variability in acute changes in muscle mass and function in older patients undergoing elective colorectal surgery, as well as feasibility of measures, in order to refine study processes to inform the protocol for a larger study.

Results: Results are presented for seven participants recruited to this pilot study. It is possible to perform serial measurements of bilateral anterior thigh thickness (BATT) and handgrip strength prior to, within $24 \mathrm{~h}$ of surgery, and 1 week postoperatively. Gait speed can be reliably measured preoperatively and at 1 week postoperatively. In this pilot study, BATT and gait speed declined at 1 week postoperatively (median BATT $4.17 \mathrm{~cm}, 3.47 \mathrm{~cm}, \mathrm{p}=0.028$; median gait speed $0.89 \mathrm{~m} / \mathrm{s}, 0.83 \mathrm{~m} / \mathrm{s}, \mathrm{p}=0.043$ ). Baseline hsCRP correlated with change in BATT ( $\mathrm{tb}=0.73, p=0.04$ ) and baseline DHEA-S correlated with change in gait speed $(\tau b=0.87, p=0.02)$. This pilot study has assisted to refine the protocol for our larger study, which will further characterise these changes.
\end{abstract}

Keywords: Acute sarcopenia, Inflammation, Biomarkers, Aged

\section{Introduction}

Sarcopenia is defined as reduced muscle mass and function [1]. European Working Group on Sarcopenia in Older People 2 (EWGSOP2) distinguishes acute from chronic sarcopenia [2]. Acute sarcopenia develops within 6 months, normally triggered by a stressor event [2]. Hospitalisation is associated with bedrest and inflammatory response, which can drive catabolism/reduce anabolism, inducing reductions in muscle mass and function; this is exacerbated by age [3, 4]. Precise mechanisms remain unclear. Overview of acute sarcopenia including proposed mechanisms and effectors has been published elsewhere [5].

Colorectal surgery is commonly performed on older adults for localised cancer resection $[6,7]$ and triggers acute inflammatory response [8]. Patients do not

*Correspondence: welchc@bham.ac.uk

1 Institute of Inflammation and Ageing, College of Medical and Dental Sciences, University of Birmingham, Edgbaston, Birmingham B15 2TT, UK

Full list of author information is available at the end of the article normally experience preoperative functional decline or cachexia [9]. Characterising acute sarcopenia in these patients will help to increase understanding, identify mechanistic pathways, and target interventions, with potential to improve postoperative recovery and longerterm physical function. This study aimed to refine the protocol for a larger study by exploring feasibility and variability of measures.

\section{Main text \\ Methods \\ Study design}

Participants were recruited from Queen Elizabeth Hospital Birmingham preoperative assessment clinic during August-October 2017. We included people aged 65 and older, planned to undergo major colorectal surgery (any indication), and able to give informed consent. Exclusion criteria were life expectancy 30 days or less and inability to understand verbal English. Known muscular disorders were not an exclusion criterion. Measurements were taken prior to admission (Visit 1), within $24 \mathrm{~h}$ of surgery 
(Visit 2), and 1 week postoperatively or day of discharge (Visit 3). A single geriatrician with training in procedures performed all assessments (CW). All assessments not possible to perform and reasons for this were recorded.

\section{Muscle mass measurement}

Quadriceps muscle thickness was measured using B-mode ultrasonography (Venue 50, GE Healthcare, UK). Participants were positioned semi-upright, with a firm wedge below the knees, and advised to relax their muscles. Measurements were taken in transverse plane at mid-point between greater trochanter and knee joint line. Thickness of subcutaneous tissue (SC), rectus femoris (RF), and vastus intermedius (VI), excluding fascia, were measured. Three measurements were taken on each side at each visit and means calculated; a fourth was taken if measurements differed more than $10 \%$. Total bilateral anterior thigh thickness (BATT) (right RF + right $\mathrm{VI}+$ left $\mathrm{RF}+$ left VI), and BATT:SC ratio (BATT-SCR) were calculated. This method has excellent intra-rater and inter-rater reliability and mean BATT correlates with bioelectrical impedance analysis (BIA) in healthy young adults [10].

\section{Muscle strength measurement}

Handgrip strength was measured at each visit using a Jamar hydraulic handheld dynamometer (Patterson Medical, Warrenville, IL, USA). Participants were positioned with elbows flexed at $90^{\circ}$, forearms in neutral position and advised to "squeeze as hard as [they] can". Highest recording of two measurements on each side was used for analysis [11].

\section{Physical performance testing}

Short Physical Performance Battery (SPPB) was scored at Visit 1; incorporates gait speed, side-by-side/tandem stand, and five chair stands [12]. We initially planned to measure SPPB at all visits; upon consideration of effect of intra-abdominal strain limiting chair stands, gait speed alone was measured at Visit 3. Gait speed is a widely accepted measure of physical performance [1, 13]. A $4 \mathrm{~m}$ course was used.

\section{Comprehensive geriatric assessment}

During Visit 1, comprehensive geriatric assessment (CGA) was performed by a single geriatrician (CW). This included Mini-Nutritional Assessment Short Form (MNA-SF) [14], Addenbrooke's Cognitive Examination-III (ACE-III) [15], evaluation of basic [16, 17] and instrumental activities of daily living (ADLs) [18], Geriatric Depression Scale Five-Point (GDS-5) [19, 20], and questioning on falls and admissions within the last year. Comorbidities and symptomatic burden were used to calculate the Geriatric Index of Comorbidity (GI-C) [21]. Frailty was defined by Fried frailty phenotype [22, 23] and Clinical Frailty Scale [24]. Delirium screening with 4AT was performed at each visit [25]. Variables measured were considered potential effectors of acute sarcopenia [5]. These were included to assess feasibility and acceptability of measurement, and document individual differences (Fig. 1).

\section{Sarcopenia definition}

This study was completed prior to EWGSOP2 dissemination; sarcopenia was defined using initial EWGSOP definition by low BATT (muscle mass) and either low handgrip strength or gait speed [1]. Cut-off values were taken two SDs below young healthy reference population means. Cut-off values were $3.86 \mathrm{~cm}$ (women) and $5.44 \mathrm{~cm}$ (men) for BATT [10], $20 \mathrm{~kg}$ (women) and $30 \mathrm{~kg}$ (men) for handgrip strength [13], and $0.8 \mathrm{~m} / \mathrm{s}$ (both genders) for gait speed [13]. Low BATT alone was defined as pre sarcopenia; severe sarcopenia was defined as all three criteria below cut-offs [1].

\section{Enzyme-linked immunosorbent assays (ELISAs)}

Blood samples were taken at Visit 1 with serum prepared within 30-60 min of collection and stored at $-80{ }^{\circ} \mathrm{C}$. Cortisol, dehydroepiandrosterone sulfate (DHEA-S), and high sensitivity C-Reactive Protein (hsCRP) (IBL International; Hamburg, Germany), and vitamin D (Immundiagnostik AG 25(OH)-vitamin D direct day ELISA; Bensheim, Germany) were measured by ELISA using commercial kits. Optical density was measured immediately using a photometer at $450 \mathrm{~nm}$ (Sci-Tek Instuments Ltd Synergy HT).

\section{Data management and analysis}

Data were entered into Microsoft Excel 2010, converted to IBM SPSS Statistics 22, and visually assessed for normality. Significance of differences between serial BATT, BATT-SCR, echogenicity, and handgrip strength were calculated using Friedman and post hoc Wilcoxon signed rank tests. Significance of difference in gait speed was calculated using Wilcoxon signed rank testing. Correlation between baseline immune-endocrine markers and changes in BATT, handgrip strength, and gait speed were assessed using Kendall's correlation. Difference in pre sarcopenia, sarcopenia, and severe sarcopenia rates between Visit 1 and Visit 3 were analysed using Chi squared test. Measurements not obtained at any visit were analysed as missing values.

\section{Ethical considerations}

Ethical approval was obtained from Wales REC 6 (17/ WA/0117). Written informed consent was obtained from 
participants. Specific optional consent was obtained to consent to remain included in the event they lost capacity to consent during the study. If this were to occur, separate consultee declaration was planned to be obtained from nominated consultees.

\section{Results}

17 patients were approached to participate in this study; eight were recruited. One participant withdrew following Visit 1; data were not analysed. One participant declined handgrip strength testing at Visit 2, and one participant declined Visit 3 assessment. Visit 3 was conducted on median day 7 (IQR 5-8). Additional file 1 shows recruitment and follow-up flowchart for this study. Table 1 displays summary statistics. Mean age was 74.7 years (SD 4.1). 85.7\% participants were male. All were White British ethnicity. All participants included in analysis underwent operations for cancer or suspected cancer (e.g. suspicious polyp) (Table 1).

\section{Changes in muscle mass and function}

BATT and BATT-SCR differed between visits $(\mathrm{p}=0.006 ; \mathrm{p}=0.006)$. Median BATT was $4.17 \mathrm{~cm}(\mathrm{IQR}$ $3.88-4.39)$ at Visit $1,5.01 \mathrm{~cm}$ (IQR 3.89-5.47) at Visit $2(\mathrm{p}=0.028$ Visit 1$)$, and $3.47 \mathrm{~cm}$ (IQR 3.21-3.81) at Visit $3(\mathrm{p}=0.028$ Visit $1 ; \mathrm{p}=0.028$ Visit 2$)$. Median BATT-SCR was 8.78 (IQR 6.67-13.08) at Visit $1,5.03$ (IQR $4.72-5.32)$ at Visit $2(\mathrm{p}=0.018$ Visit 1$)$, and 3.94 (IQR 2.82-5.01) at Visit $3(\mathrm{p}=0.028$ Visit $1 ; \mathrm{p}=0.046$ Visit 2). There was no significant change in handgrip strength $(\mathrm{p}=0.692)$. Gait speed declined from median $0.89 \mathrm{~m} / \mathrm{s}$ (IQR $0.78-1.06$ ) at Visit 1 to median $0.83 \mathrm{~m} / \mathrm{s}$ (IQR $0.68-0.91)$ at Visit $3(\mathrm{p}=0.043)$. Results are shown in Fig. 1a-c.

\section{Acute sarcopenia}

Prevalence of sarcopenia at baseline was $28.6 \%$. As assessments were not performed on one participant at Visit 3, incidence of acute sarcopenia at Visit 3 was $75 \%$. Overall prevalence of sarcopenia at Visit 3 was $83.3 \%$. One participant, who had pre sarcopenia at Visit 1, developed severe sarcopenia. Changes were not statistically significant $(\mathrm{p}=0.558)$. Results are shown in Fig. $1 \mathrm{~d}$.

\section{Immune-endocrine markers}

There was a positive association between baseline DHEA-S and gait speed change $(\mathrm{rb}=0.87$, $\mathrm{p}=0.02$ ) (Fig. 2a), and between baseline hsCRP and BATT change $\mathrm{tb}=0.73, \mathrm{p}=0.04$ ) (Fig. $2 \mathrm{~b}$ ). No other significant associations were identified.
Table 1 Demographics and basic participant information

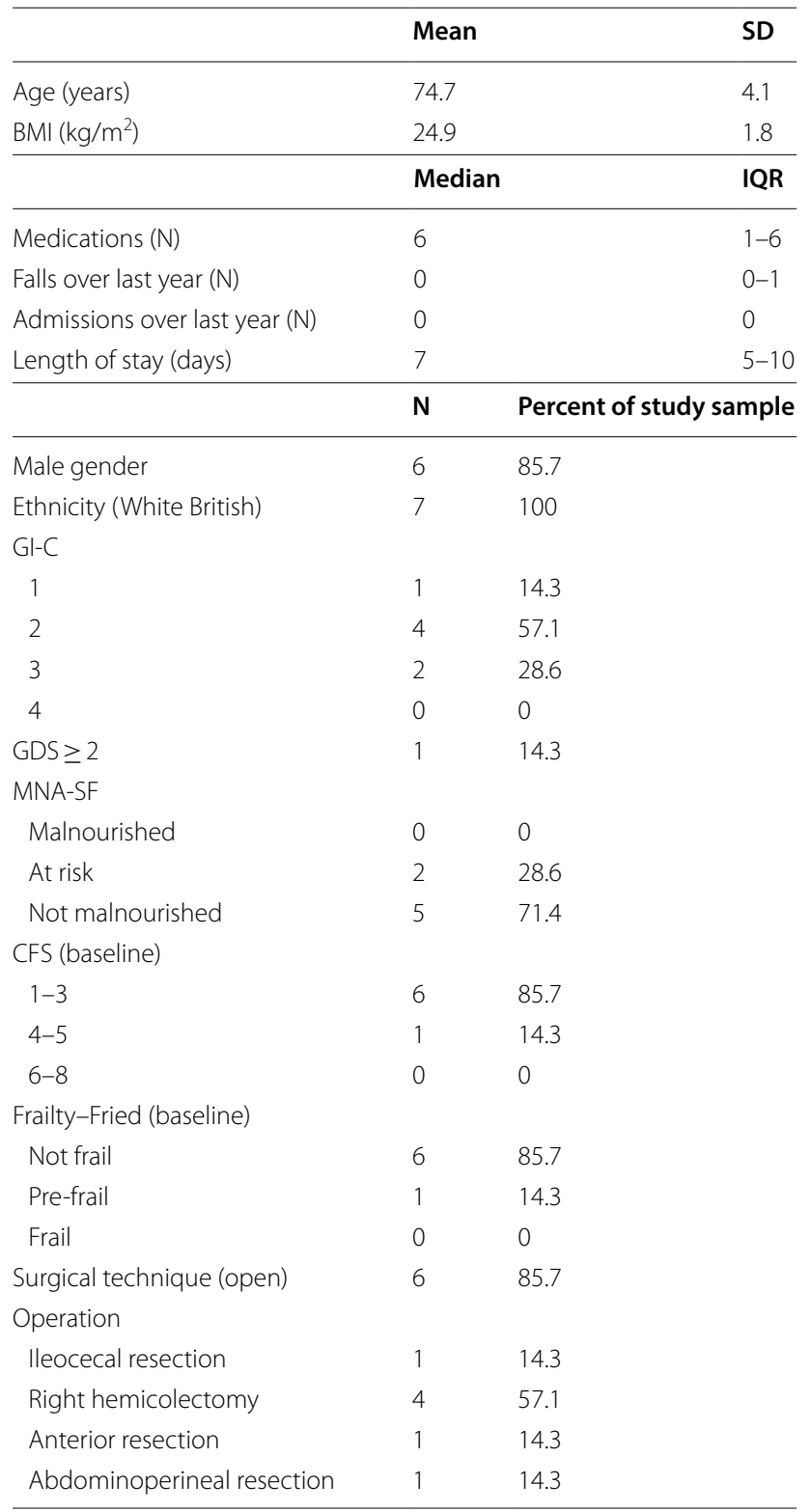

The mean age of participants was 74.7 years, with $85.7 \%$ being of a male gender. $100 \%$ of participants were White British. $85.7 \%$ of participants were not frail at baseline by CFS and Fried criteria. Operations performed included ileocecal resection, right hemicolectomy, anterior resection, and abdominoperineal resection. $85.7 \%$ were performed as open procedures

\section{Feasibility and acceptability of measurements}

It was possible to perform all muscle assessments in all participants at Visit 1. BATT was measured at each visit with participants, although one participant declined all assessments at Visit 3. One participant declined handgrip strength assessment at Visit 2. SPPB was measured at baseline; only gait speed was measured at Visit 3, due to potential harm from abdominal strain in performing chair stands. Nutritional, mood, functional, and 

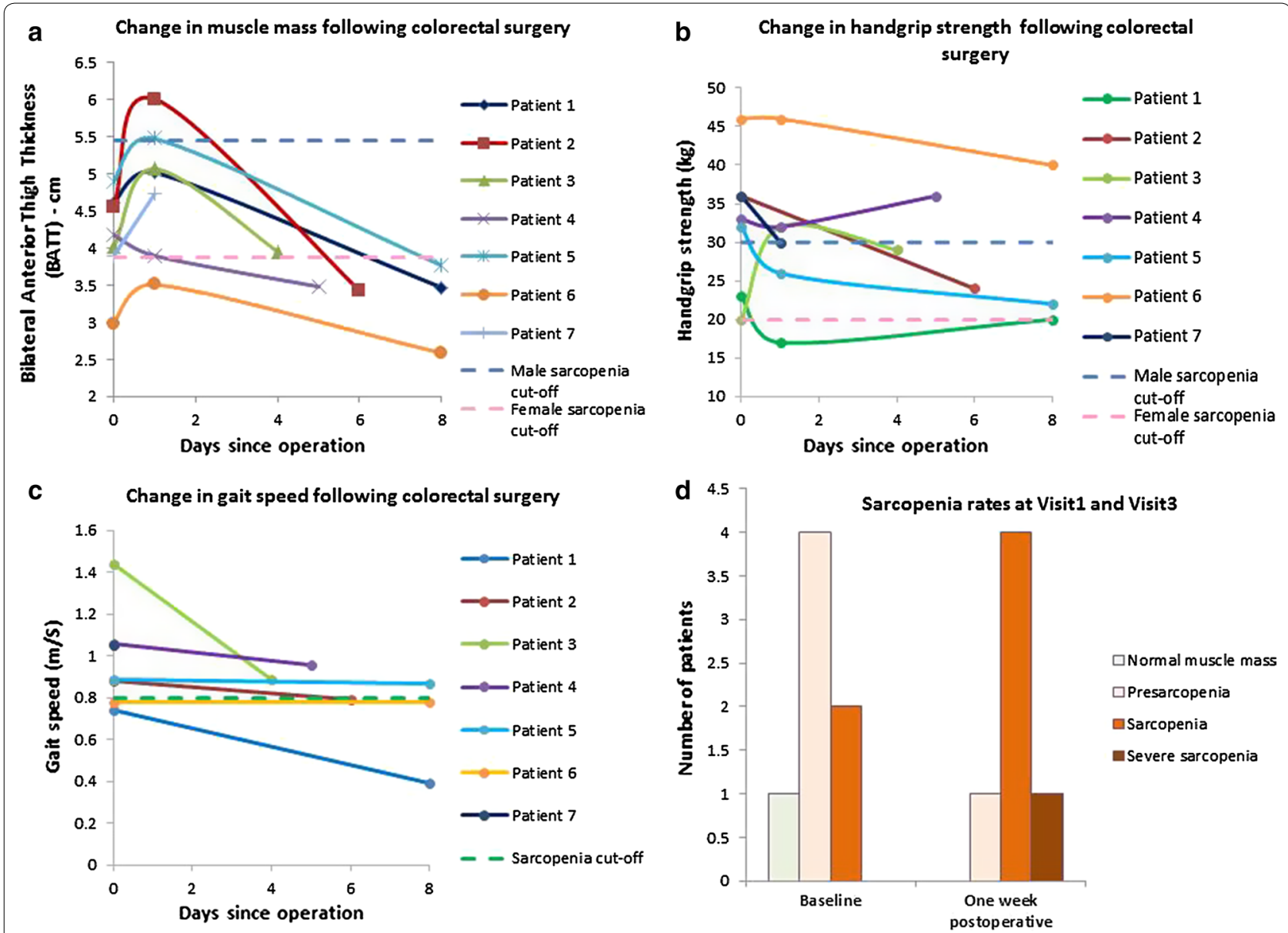

Fig. 1 Change in muscle mass and function measured during this pilot study. BATT increased within $24 \mathrm{~h}$ of surgery and declined at visit 3 (a). Handgrip strength varied widely; two participants experienced increases in handgrip strength and the rest experienced decreases (b). Gait speed declined from visit 1 to visit 3 (c). Although not statistically significant in this pilot, there was a higher prevalence of sarcopenia at visit 3 compared to visit 1 (d). Cut-off points are indicated [BATT $3.86 \mathrm{~cm}$ (women), $5.44 \mathrm{~cm}$ (men); muscle strength $20 \mathrm{~kg}$ (women), $30 \mathrm{~kg}$ (men); gait speed $0.8 \mathrm{~m} / \mathrm{s}$ (both genders)]

comorbidity assessment were performed in all participants at Visit 1 . Cognitive screening was initially performed, but following withdrawal of one participant due to burden of assessment, a decision was made to remove formal cognitive testing. Participants expressed they found all other assessments acceptable. No participant exhibited loss of capacity, but all participants consented to ongoing inclusion in the event they should have lost capacity during the study.

\section{Discussion}

Prevalence of sarcopenia at Visit 1 was similar to previous studies in hospitalised older patients [26-29]. Reduction in BATT and gait speed, and increased prevalence of sarcopenia at Visit 3 compared to Visit 1 was demonstrated. Muscle strength change showed greater variability between participants. The next stage of our research will characterise a larger cohort, including elective and emergency admissions, and include three-month followup. We have shown that measurement of these variables is feasible in an acute care setting. Due to perceived burden of ACE-III, and following further public involvement, this will not be measured in our main study. This should enable time to focus on nutritional and physical function assessment, and comparison measurements of muscle mass with BIA.

BATT increased at Visit 2 in all but one participant; BATT-SCR reduced across visits for all participants. This suggests increased BATT was associated with increased SC thickness. We consider increased SC thickness more likely represents oedema than increase in fat tissue. Similar findings have been demonstrated in critical care patients following cardiothoracic surgery, with quadriceps muscle thickness correlating with fluid balance [30]. However, changes in fluid balance alone may 

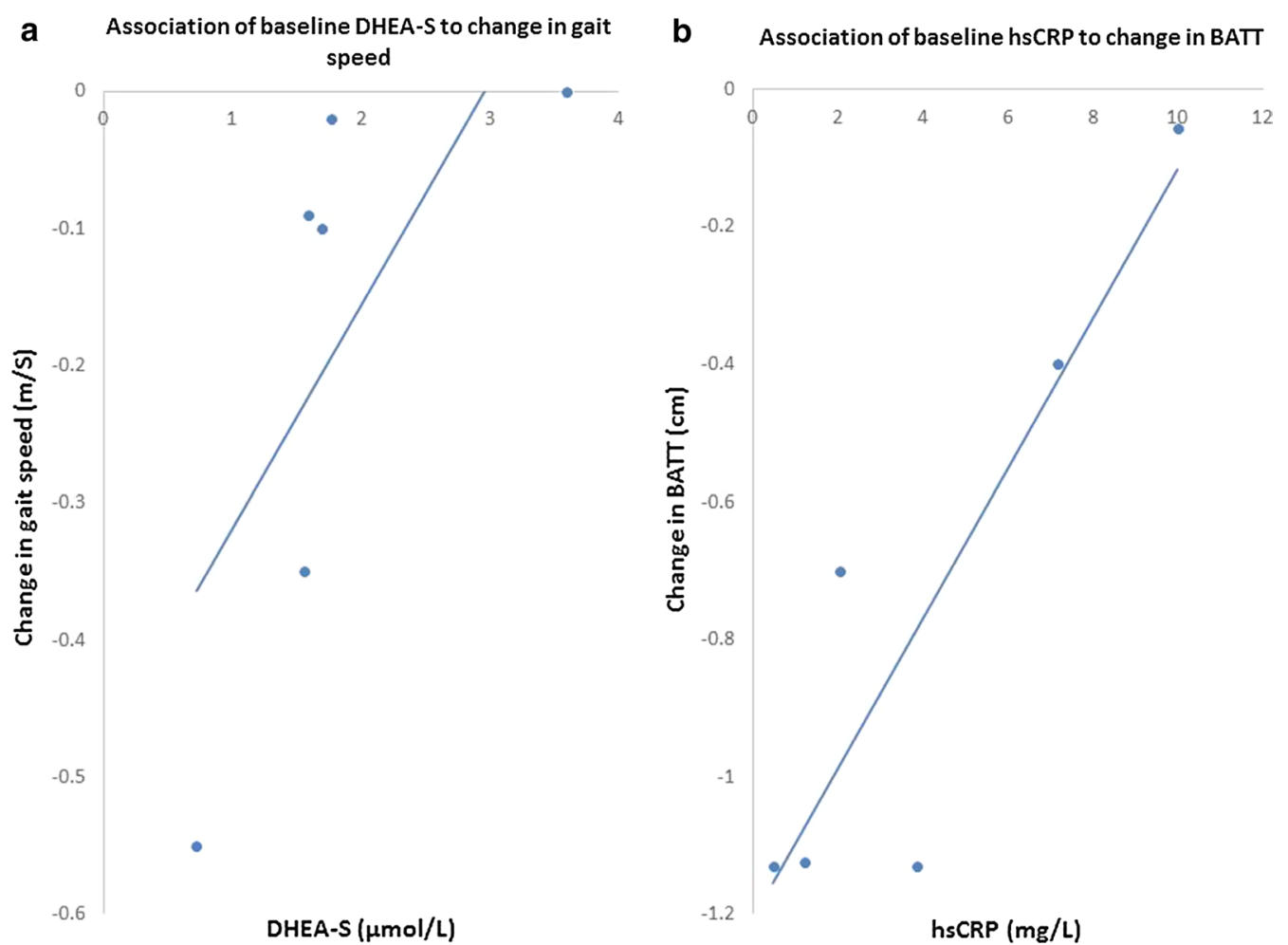

Fig. 2 Association of DHEA-S to change in gait speed and hsCRP to change in BATT. There was a positive association between baseline DHEA-S and change in gait speed $(\tau b=0.87, p=0.02)(\mathbf{a})$ and a positive association between baseline hsCRP and change in BATT $(\tau b=0.73, p=0.04)(\mathbf{b})$

be insufficient to explain this. Fluid shifts may have been exacerbated by systemic inflammation and increased vascular permeability postoperatively [31]. Considering increases in BATT within $24 \mathrm{~h}$ of surgery may represent heightened systemic inflammation, this should not be disregarded as a benign process. If acute increase in BATT relates to increased inflammation, this could herald increased likelihood of developing acute sarcopenia. Our planned larger study will assess if rate of change to Visit 2 predicts rate of change to Visit 3.

Baseline hsCRP correlated with change in BATT to Visit 3, suggesting older adults with lower baseline inflammation were at greater risk of acute reductions in muscle size. This is converse to associations demonstrated in chronic sarcopenia; higher levels of hsCRP and proinflammatory cytokines have been demonstrated in older adults with sarcopenia [32] although, a positive association between hsCRP and lean appendicular mass was demonstrated in a large cohort study [33]. Baseline DHEA-S levels correlated with change in gait speed; agerelated reduced DHEA-S has been shown to correlate with reduced physical performance [34]. We will further evaluate this in our larger study; a proven association may suggest exogenous DHEA-S could be used to protect older adults from acute declines in physical performance.
Our main study will fully characterise acute muscle changes, and acute sarcopenia in elective and emergency patients. This will include CGA, particularly nutritional and physical function assessment, and measurement of biomarkers of immune-endocrine function, as guided by our pilot results. Follow-up will be conducted to assess if acute changes in muscle mass and function are predictive of change in physical function at 3 months.

\section{Limitations}

Firstly, we recognise that, although tests of statistical significance were performed, this pilot study was not powered to identify changes in muscle mass or function. We fully acknowledge that no definite conclusions can be made from this study alone. However, we consider these results may be of value in future research and, potentially, used in a systematic review. Our results have reaffirmed the need for our larger study, and assisted with power calculations.

An important characteristic that differed from expected population within this study was gender. Percentage of elective colorectal surgery procedures performed on females has been reported as $41.7-56.2 \%$ [35-37]. This is important as muscle echotexture, muscle: $\mathrm{SC}$ tissue 
ratio, and muscle force generation and relaxation are reported to differ between genders [38]. We acknowledge that analysis of genders together may have confounded results.

All assessments were performed by a single investigator. Although this ensured standardisation of technique, this may have induced systematic error. Handgrip strength is recommended to be measured with the participant sat upright and elbow flexed at $90^{\circ}$. Measurements were taken in this position wherever the participant was able to sit out; however, in some circumstances at Visit 2 this was not possible. In these cases, handgrip strength was assessed with the participant in a semi-upright position in bed with elbow flexed as close to $90^{\circ}$ as possible. This may have affected results at this time point.

Lastly, there is some evidence that position of the participant when measuring quadriceps thickness can affect results [39]. Measurement has been recommended with the participant lying supine, as most objectively standardised position [40]. However, some participants were unable to lie flat at Visit 2, due to increased intraabdominal strain and postoperative nausea. Therefore, ultrasound assessments were performed in a semi-upright position. An attempt was made to standardise this position as much as possible, but this was not assessed objectively; there may have been some variability in bed position between visits. Measurements taken in the reference population were taken in a similar position [10].

\section{Additional file}

Additional file 1. Recruitment and follow-up flowchart. Flowchart to clearly demonstrate recruitment, enrolment, and follow-up of participants within this research study.

\section{Abbreviations}

4AT: 4 "A"s test; ADL: activity of daily living; BATT: bilateral anterior thigh thickness; BATT-SCR: bilateral anterior thigh thickness: Subcutaneous tissue ratio; BIA: bioelectrical impedance analysis; CFS: Clinical Frailty Scale; DHEA-S: dehydroepiandrosterone sulfate; ELISA: enzyme-linked immunosorbant assay; GDS-5: Geriatric Depression Scale 5; GI-C: Geriatric Index of Comorbidity; hsCRP: high sensitivity C-Reactive Protein; IQR: interquartile range; MNA-SF: Mini Nutritional Assessment (Short Form); RF: rectus femoris; SC: subcutaneous tissue; SPPB: Short Physical Performance Battery; Vl: vastus intermedius.

\section{Authors' contributions}

CW performed all data collection and analysis. CAG, ZKH, TP, JML, and TAJ all provided specialist expertise in the design of the protocol and throughout conduct of the study. All authors read and approved the final manuscript.

\section{Author details}

${ }^{1}$ Institute of Inflammation and Ageing, College of Medical and Dental Sciences, University of Birmingham, Edgbaston, Birmingham B15 2TT, UK.

${ }^{2}$ Queen Elizabeth Hospital Birmingham, Mindelsohn Way, Edgbaston, Birmingham B15 2GW, UK. ${ }^{3}$ School of Sport, Exercise \& Rehabilitation Sciences,
University of Birmingham, Edgbaston, Birmingham, B15 2TT, UK. ${ }^{4} \mathrm{MRC}$ Arthritis Research UK Centre for Musculoskeletal Ageing Research, University of Birmingham, Edgbaston, Birmingham B15 2TT, UK. ${ }^{5}$ National Institute for Health Research (NIHR), Birmingham Biomedical Research Centre, University of Birmingham, Edgbaston, Birmingham B15 2TT, UK. ${ }^{6}$ Centre for Endocrinology, Diabetes and Metabolism, Birmingham Health Partners, University of Birmingham, Edgbaston, Birmingham B15 2TT, UK. ${ }^{7}$ Academic Department of Surgery, Room 29, 4th Floor, Heritage Building, Edgbaston, Birmingham B15 $2 \mathrm{TH}, \mathrm{UK}$.

\section{Acknowledgements}

Not applicable.

\section{Competing interests}

The authors declare that they have no competing interests.

\section{Availability of data and materials}

Datasets used and analysed during this study are available from the corresponding author upon reasonable request.

\section{Consent for publication}

Not applicable.

\section{Ethics approval and consent to participate}

Ethical approval was obtained from Wales REC 6 (17/WA/0117), the Health Research Authority (HRA) and the University Hospitals Birmingham NHS Trust Research \& Development (R\&D) department (RRK6018). Written informed consent was obtained from all participants.

\section{Funding}

This research project was funded by a British Geriatrics Society (BGS) Start-Up Grant. Dr. Carly Welch is funded by a National Institute for Health (NIHR) Academic Clinical Fellowship. The views expressed are those of the authors and not necessarily those of the National Health Service (NHS), NIHR, or Department of Health. The funders were not involved in the design of the study, collection, analysis or interpretation of data, or in writing the manuscript.

\section{Publisher's Note}

Springer Nature remains neutral with regard to jurisdictional claims in published maps and institutional affiliations.

Received: 2 October 2018 Accepted: 4 January 2019

Published online: 14 January 2019

\section{References}

1. Cruz-Jentoft AJ, Baeyens JP, Bauer JM, Boirie Y, Cederholm T, Landi F, et al. Sarcopenia: European consensus on definition and diagnosis: report of the European Working Group on sarcopenia in older people. Age Ageing. 2010;39(4):412-23.

2. Cruz-Jentoft AJ, Bahat G, Bauer J, Boirie Y, Bruyère O, Cederholm T, et al. Sarcopenia: revised European consensus on definition and diagnosis. Age Ageing. 2018.

3. Kortebein P, Ferrando A, Lombeida J, Wolfe R, Evans WJ. Effect of 10 days of bed rest on skeletal muscle in healthy older adults. JAMA. 2007:297(16):1772-4.

4. Tanner RE, Brunker LB, Agergaard J, Barrows KM, Briggs RA, Kwon OS, et al. Age-related differences in lean mass, protein synthesis and skeletal muscle markers of proteolysis after bed rest and exercise rehabilitation. J Physiol. 2015;593(18):4259-73.

5. Welch C, Hassan-Smith Z, Greig C, Lord J, Jackson T. Acute sarcopenia secondary to hospitalisation-an emerging condition affecting older adults. Aging Dis. 2018;9(1):151-64.

6. Cancer Research UK. Bowel cancer incidence statistics-bowel cancer incidence by age 2018. https://www.cancerresearchuk.org/health-profe ssional/cancer-statistics/statistics-by-cancer-type/bowel-cancer/incid ence. Accessed 26 Sept 2018. 
7. The Royal College of Surgeons of England. Access all ages: assessing the impact of ages on access to surgical treatment 2012.

8. Smeets BJJ, Brinkman DJ, Horsten ECJ, Langius JAE, Rutten HJT, de Jonge WJ, et al. The effect of myopenia on the inflammatory response early after colorectal surgery. Nutr Cancer. 2018;70(3):460-6.

9. Fox KM, Brooks JM, Gandra SR, Markus R, Chiou CF. Estimation of cachexia among cancer patients based on four definitions. J Oncol. 2009;2009:693458.

10. Wilson D. Frailty, sarcopenia and immunesenescence: shared mechanisms and clinical insights. Ph.D., University of Birmingham; 2018.

11. Roberts HC, Denison HJ, Martin HJ, Patel HP, Syddall H, Cooper C, et al. A review of the measurement of grip strength in clinical and epidemiological studies: towards a standardised approach. Age Ageing. 2011;40(4):423-9.

12. Guralnik JM, Simonsick EM, Ferrucci L, Glynn RJ, Berkman LF, Blazer DG, et al. A short physical performance battery assessing lower extremity function: association with self-reported disability and prediction of mortality and nursing home admission. J Gerontol. 1994;49(2):M85-94.

13. Lauretani F, Russo CR, Bandinelli S, Bartali B, Cavazzini C, Di lorio A, et al. Age-associated changes in skeletal muscles and their effect on mobility: an operational diagnosis of sarcopenia. J Appl Physiol. 2003;95(5):1851-60.

14. Nestlé Nutrition Institute. Mini Nutritional Assessment 2009. https://www. mna-elderly.com/forms/mini/mna_mini_english.pdf. Accessed 12 Sept 2017.

15. Hsieh S, Schubert S, Hoon C, Mioshi E, Hodges JR. Validation of the Addenbrooke's Cognitive Examination III in frontotemporal dementia and alzheimer's disease. Dement Geriatr Cogn Disord. 2013;36(3-4):242-50.

16. Katz S, Downs TD, Cash HR, Grotz RC. Progress in development of the index of ADL. Gerontologist. 1970;10(1):20-30.

17. Katz S, Ford AB, Moskowitz RW, Jackson BA, Jaffe MW. Studies of illness in the aged: The index of adl: a standardized measure of biological and psychosocial function. JAMA. 1963;185(12):914-9.

18. Lawton MP, Brody EM. Assessment of older people: self-maintaining and instrumental activities of daily living. Gerontologist. 1969;9(3):179-86.

19. Rinaldi P, Mecocci P, Benedetti C, Ercolani S, Bregnocchi M, Menculini $G$, et al. Validation of the five-item geriatric depression scale in elderly subjects in three different settings. J Am Geriatr Soc. 2003;51(5):694-8.

20. Mitchell AJ, Bird V, Rizzo M, Meader N. Which version of the geriatric depression scale is most useful in medical settings and nursing homes? Diagnostic validity meta-analysis. Am J Ger Psychiatry. 2010;18(12):1066-77.

21. Zekry D, Loures Valle BH, Lardi C, Graf C, Michel JP, Gold G, et al. Geriatrics index of comorbidity was the most accurate predictor of death in geriatric hospital among six comorbidity scores. J Clin Epidemiol. 2010;63(9):1036-44

22. Fried LP, Tangen CM, Walston J, Newman AB, Hirsch C, Gottdiener J, et al. Frailty in older adults: evidence for a phenotype. J Gerontol Ser A Biol Sci Med Sci. 2001;56(3):M146-56.

23. Cesari M, Gambassi G, van Abellan Kan G, Vellas B. The frailty phenotype and the frailty index: different instruments for different purposes. Age Ageing. 2014;43(1):10-2.

24. Dalhousie University. Clinical Frailty Scale 2007. http://geriatricresear ch.medicine.dal.ca/clinical_frailty_scale.htm. Accessed 5 Nov 2018.
25. Bellelli G, Morandi A, Davis DH, Mazzola P, Turco R, Gentile S, et al. Validation of the 4AT, a new instrument for rapid delirium screening: a study in 234 hospitalised older people. Age Ageing. 2014;43(4):496-502.

26. Martinez BP, Batista AK, Gomes IB, Olivieri FM, Camelier FW, Camelier AA. Frequency of sarcopenia and associated factors among hospitalized elderly patients. BMC Musculoskelet Disord. 2015;16:108.

27. Rossi AP, Fantin F, Micciolo R, Bertocchi M, Bertassello P, Zanandrea V, et al. Identifying sarcopenia in acute care setting patients. J Am Med Dir Assoc. 2014:15(4):303.e7-12.

28. Sousa AS, Guerra RS, Fonseca I, Pichel F, Amaral TF. Sarcopenia among hospitalized patients-a cross-sectional study. Clin Nutr. 2015;34(6):1239-44

29. Smoliner C, Sieber CC, Wirth R. Prevalence of sarcopenia in geriatric hospitalized patients. J Am Med Dir Assoc. 2014;15(4):267-72.

30. Fischer A, Spiegl M, Altmann K, Winkler A, Salamon A, Themessl-Huber $\mathrm{M}$, et al. Muscle mass, strength and functional outcomes in critically ill patients after cardiothoracic surgery: does neuromuscular electrical stimulation help? The Catastim 2 randomized controlled trial. Crit Care. 2016;20:30

31. Claesson-Welsh L. Vascular permeability - the essentials. Upsala J Med Sci. 2015;120(3):135-43.

32. Bano G, Trevisan C, Carraro S, Solmi M, Luchini C, Stubbs B, et al. Inflammation and sarcopenia: a systematic review and meta-analysis. Maturitas. 2017:96:10-5.

33. Westbury LD, Fuggle NR, Syddall HE, Duggal NA, Shaw SC, Maslin K, et al. Relationships between markers of inflammation and muscle mass, strength and function: findings from the Hertfordshire Cohort Study. Calcif Tissue Int. 2018;102(3):287-95.

34. Rendina DN, Ryff CD, Coe CL. Precipitous dehydroepiandrosterone declines reflect decreased physical vitality and function. J Gerontol Ser A Biol Sci Med Sci. 2017:72(6):747-53.

35. Ahmed J, Lim M, Khan S, McNaught C, Macfie J. Predictors of length of stay in patients having elective colorectal surgery within an enhanced recovery protocol. Int J Surg. 2010;8(8):628-32.

36. Collaborative YSR. Multicentre observational study of gastrointestinal recovery after elective colorectal surgery. Colorectal Dis. 2018;20(6):536-44.

37. Fagard K, Casaer J, Wolthuis A, Flamaing J, Milisen K, Lobelle JP, et al. Postoperative complications in individuals aged 70 and over undergoing elective surgery for colorectal cancer. Colorectal Dis. 2017;19(9):0329-38.

38. Haizlip KM, Harrison BC, Leinwand LA. Sex-based differences in skeletal muscle kinetics and fiber-type composition. Physiology. 2015:30(1):30-9.

39. Hacker ED, Peters T, Garkova M. Ultrasound assessment of the rectus femoris cross-sectional area: subject position implications. West J Nurs Res. 2016;38(9):1221-30

40. Strasser EM, Draskovits T, Praschak M, Quittan M, Graf A. Association between ultrasound measurements of muscle thickness, pennation angle, echogenicity and skeletal muscle strength in the elderly. Age. 2013;35(6):2377-88

Ready to submit your research? Choose BMC and benefit from

- fast, convenient online submission

- thorough peer review by experienced researchers in your field

- rapid publication on acceptance

- support for research data, including large and complex data types

- gold Open Access which fosters wider collaboration and increased citations

- maximum visibility for your research: over 100M website views per year

At BMC, research is always in progress.

Learn more biomedcentral.com/submissions 